\title{
CORRECTION
}

View Article Online

View Journal I View Issue

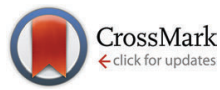

Cite this: J. Mater. Chem. C, 2015, 3, 2960

DOI: $10.1039 /$ c5tc90044a

www.rsc.org/MaterialsC

\section{Correction: Transistor application of new picene-type molecules, 2,9-dialkylated phenanthro[1,2-b:8,7-b']dithiophenes}

\author{
Yoshihiro Kubozono, ${ }^{\text {abc }}$ Keita Hyodo, ${ }^{d}$ Hiroki Mori, ${ }^{d}$ Shino Hamao, ${ }^{a}$ Hidenori Goto ${ }^{a}$ \\ and Yasushi Nishihara*bcd
}

Correction for 'Transistor application of new picene-type molecules, 2,9-dialkylated phenanthro[1,2-b:8,7- $b^{\prime}$ ]dithiophenes' by Yoshihiro Kubozono et al., J. Mater. Chem. C, 2015, 3, DOI: 10.1039/c4tc02413c.

There are some additional corrections that apply to this article and were only found after publication of the final version of the article. They are detailed as follows:

On the right column of page 3 of the article, in "C 7 -PTD", "PTD" should read "PDT".

On line 7 of the left column of page 5 of the article, a minus sign was omitted and the value $5.7 \mathrm{eV}$ should be $-5.7 \mathrm{eV}$.

On the right column of page 5 of the article, " $\mathrm{C}_{12} \mathrm{H}_{29}$ " should be " $\mathrm{C}_{12} \mathrm{H}_{25}$ ".

On the left column of page 7 of the article, the units mm should be $\mu \mathrm{m}$ in " $L=135,200$ and $300 \mu \mathrm{m}$ ".

The Royal Society of Chemistry apologises for these errors and any consequent inconvenience to authors and readers.

\footnotetext{
${ }^{a}$ Research Laboratory for Surface Science, Okayama University, Okayama 700-8530, Japan. E-mail: kubozono@cc.okayama-u.ac.jp

${ }^{b}$ Research Center of New Functional Materials for Energy Production, Storage and Transport, Okayama University, Okayama 700-8530, Japan

'Japan Science and Technology Agency, ACT-C, 4-1-8 Honcho, Kawaguchi, Saitama 332-0012, Japan

${ }^{d}$ Division of Earth, Life, and Molecular Sciences, Graduate School of Natural Science and Technology, Okayama University, 3-1-1 Tsushimanaka, Kita-ku,

Okayama 700-8530, Japan
} 